\section{Moyamoya Disease -Factors and Prevalence for Perivascular Spaces in Post-Neurological Adult Patients: Neurosurgeon's Perspective}

\author{
Dennis Adjepong* iD \\ California Institute of Behavioral Neuroscience \& Psychology, USA
}

\begin{abstract}
Moyamoya disease is a blood vessel disorder that occurs in the brain on the internal carotid arteries and its branches. The blood vessel in the carotid artery is narrowed and blocked, reducing and preventing blood flow to the brain. The condition results in the narrowing of the vessels distributing oxygen-rich blood to the brain. This report explores the results and effects of the disease, its pathophysiological, biochemical, genetics and scientific analysis of the disease. This also includes the clinical implementations and unanswered questions concerning the moyamoya disease.
\end{abstract}

Keywords: Enlarged perivascular space; Moyamoya disease; Vascular disease

\section{Introduction}

The Moyamoya disease was named from a Japanese meaning 'puff of smoke', usually resulting from blocked arteries at the brains base. It often appears as tiny blood vessels that form to compensate for the blocked artery. As the blood vessel becomes more blocked, individuals are more likely to suffer from stroke. The condition results in the narrowing of the vessels distributing oxygen-rich blood to the brain [1]. The primary characteristic of moyamoya disease is chronic progressive stenosis which affects the internal carotid artery [2]. A vascular network with abnormality is formed at the base of brain by

*Corresponding author: Dennis Adjepong, California Institute of Behavioral Neuroscience \& Psychology, USA, Tel: +1 5712771998; Fax: +1 8044091695; Email: dennisadjepong@gmail.com

Citation: Adjepong D (2020) Moyamoya Disease -Factors and Prevalence for Perivascular Spaces in Post-Neurological Adult Patients: Neurosurgeon's Perspective. J Emerg Med Trauma Surg Care 7: 045.

Received: March 26, 2020; Accepted: May 09, 2020; Published: May 15, 2020

Copyright: (C) 2020 Adjepong D. This is an open-access article distributed under the terms of the Creative Commons Attribution License, which permits unrestricted use, distribution, and reproduction in any medium, provided the original author and source are credited. the stenosis, which also reduces cerebral blood flow and perfusion pressure [3]. Moyamoya disease patients have an increased risk of developing EPVs (enlarged perivascular spaces), which mainly affect female adult patients who have high flow of voids and basal ganglia, high resonance angiography scores detecting coronary stenosis regarding calcium scores in the body, white matter lesions, and ivy signs including swelling, redness, itching, blisters, and difficulties breathing [4]. Flow of voids refer to the signal loss of blood and other fluids with a combination of spin-phase and time-of-flight effects. EPVs are detected through a T2-weighted MRI and they indicate the presence of small vessel disease. The rare disease is progressive, with an appearance of a puff of smoke in the brain area [5]. It is unfortunate that moyamoya is not curable [6]. However, experts suggest that a cerebral revascularization and vascular bypass surgery are considered effective as they help in diverting blood to nearby muscles from the blood vessel, with oxygen finally reaching the oxygen stared brain areas, also reducing the risks of stroke and long-term drastic outcomes [7]. The purpose of this study will be to explore the moyamoya disease through data collection, exploration of the results, pathophysiology, biochemical, genetics, and scientific analysis, later analyzing its clinical implications among other unaddressed issues concerning the disease.

\section{Discussion}

\section{Pathophysiology of disease}

Moyamoya disease mainly affects the children and the elderly. Research has identified that the Chinese, Korean, and Japanese are at higher risk of getting the disorder [8]. The disorder is also progressive and cannot stop without treatment. Again, it is not curable, but brain surgery is considered the only option to guarantee blood flow back to the brain [9]. Mainly, the pathophysiology of moyamoya disease is unclear. However, it is usually an abnormal cerebrovascular condition whereby patients experience abnormal perforation of blood vessels guaranteeing collateral circulation [10]. The chronic progressive disease has been reported given the increased use of advanced diagnostic radiology systems and medical check-ups [4]. The pathogenesis and etiology of the disease remain unclear. Evidence suggests that the underlying cause of the moyamoya disease is vascular anomalies within the endothelial progenitor cells [11]. Currently, it affects about $15 \%$ of patients through autosomal dominant inheritance patterns [12]. Genome-wide studies and genetic analysis on moyamoya disease proves promising to identify the exact pathophysiology of the condition [13].

\section{Biochemistry of disease}

Moyamoya disease (MMD) involves the major stenosis of vessels of the circle of Willis [3]. The major proteins involved play active roles during the pathogenesis of the disease including basic fibroblast, vascular endothelial, Beta 1, and hepatocyte growth factor [14]. Further studies have also linked reduced angiogenic activity and with moyamoya disease among patients. Most believe that RNF213 and R $4810 \mathrm{~K}$ prove the susceptibility of mutations with the disease [15]. 


\section{Genetics of the disease}

Recent research showed low penetrance polygenic mode or autosomal dominance transmissions involving the chromosome 3,6,12, 17, and 8 familial with moyamoya disease [16]. Scholars argue that this way, the disease can be passed through genes from families over hereditary periods. Moyamoya has also been associated with RNF213 [7]. Other studies argue that an excess of proteins at these cells stimulate blood vessels to grow, hence the characteristics leading to the [12]. The symptomatic of these processes include insufficient blood supply in the body cells, hence the rupture of collaterals causing stroke and death to the patient. Genetic approaches hence locate susceptibility of loci in affected families to guarantee a successful understanding of the disease [17].

\section{Scientific Analysis}

An accurate analysis of moyamoya disease often involves diagnosis in the clinical setting. The diagnosis process involves MRI imaging to depict the reduced blood flow at the anterior and middle cerebral arteries and internal carotid artery [3]. The imaging shows increased collateral blood, hence confirming the disease [7]. This process also requires an angiogram. Abnormal vascular networks often develop on the stenotic lesions or occlusive in the arterial phase. MR imaging shows the occlusion or stenosis of the middle cerebral artery (MCA) or anterior cerebral ACA [18]. From the beginning, it is evident that moyamoya disease did not depict stenotic changes at the ICA terminal region [19]. The second option integrated is the Suzuki angiographic staging, with is being effective in understanding its pathology among each patient. The staging method also shows the severity of the disease in the Internal carotid artery (ICA) region and subsequent vessels [1]. Thirdly, supportive findings through genetic evaluations and histopathological analysis help understand the susceptibility of the gene among populations [15]. Histological analysis of specimens at surgery and autopsy supports the diagnosis of the diseases, with genes RNF213 and 17q25-ter proving high susceptibility for moyamoya disease [2].

\section{The Clinical Implication of Disease}

Firstly, moyamoya disease is associated with diseases such as Graves disease among other chronic illnesses among patients [20]. Others experience cerebrovascular ischemic effects that may result in thyrotoxicosis, including an excessive demand for oxygen given the deficit at the cerebral blood flow [21]. The disease has multiple clinical features, whereby the doctor must be informed in case they appear. Most patients have two peaks at the age of 5 and 40 years, with pediatric patients posing a higher likelihood of having ischemic attacks and intracranial bleeding [10,20]. Down syndrome and thyroid dysfunction have been strongly linked and interrelated to each other [22]. High levels of thyroid risk causing vascular changes and altering the sympathetic stimuli sensitivity [23]. If the graves' disease is not treated, it increases the stiffness of carotid arteries as it is the case with ultrasonography [21]. The most common symptoms of the disease include seizures at an early age, headache, cognitive decline, developmental delays, visual disturbances, weakness and numbness in the body and joints [24].

\section{The Unanswered Questions}

Most of the unanswered questions about moyamoya disease include the lack of an exact biological, genetic, biochemical, pathophysiology, and genetics of the disease [15]. This means that more research must be conducted to guarantee that clinicians find the best way to prevent the disease in the future [25].

\section{Conclusion}

This study confirmed an increase in the prevalence rate of EPVs among moyamoya disease patients. The presence of other health condition such as hypertension, basal ganglia, and flow voids also increased the risk factor among female patients. Reduced pulsation of the arterial is the major contributor of the increased rate as it inhibits interstitial fluid flow [26,27]. Following the systematic studies, moyamoya disease proved to continually affect many individuals across the states. It is the role of the government and healthcare institutions to ensure that they find more research and analysis on moyamoya disease to identify the probable causes of the disease and ways to guarantee patients protection and prevention from the disorder. All patients with the disorder are required to visit the doctor immediately, ensuring that they are treated to prevent the severity of their illness. It is also important to conduct further research on patients with moyamoya disease to create an understanding of the pathophysiological importance of EPVs and how they can be prevented after performing a surgery on the patients $[28,29]$.

\section{References}

1. Gattozzi DA, Faheem N, Madarang EJ, Gronseth GS, Camarata PJ (2019) Correlation of Petrous Carotid Canal Diameter with Severity of Ipsilateral Moyamoya Disease. J Neurol Surg Part B 80: A054.

2. Feghali J, Xu R, Yang W, Liew JA, Blakeley J, et al. (2019) Moyamoya disease versus moyamoya syndrome: comparison of presentation and outcome in 338 hemispheres. J Neurosurg 1: 1-9.

3. Blanchard KG, Frey D, Schenkel T, Prinz V, Bedini G, et al. (2017) Autocrine release of angiopoietin-2 mediates cerebrovascular disintegration in Moyamoya disease. J Cereb Blood Flow Metab 37: 1527 1539.

4. Kobayashi H, Matsuda Y, Hitomi T, Okuda H, Shioi H, et al. (2015) Biochemical and functional characterization of RNF213 (Mystery) $\mathrm{R} 4810 \mathrm{~K}$, a susceptibility mutation of moyamoya disease, in angiogenesis in vitro and in vivo. J Am Heart Assoc 4: e002146.

5. Tharayil AM, Ganaw AE, Shaikh N, Prabhakaran SM, Chanda AH, et al. (2019) Moyamoya Disease: A Rare Vascular Disease of the CNS. In: Vascular Malformations of the Central Nervous System. In: tech Open.

6. Morshed RA, Murph D, Dao J, Colao K, Avalos L, et al. (2019) Clinical and Imaging Outcomes After Combined Direct and Indirect Bypass for Pediatric Moyamoya Disease: A Single-Center Retrospective Series. Neurosurg 66: nyz310_658.

7. Fujimura M, Sonobe S, Nishijima Y, Niizuma K, Sakata H, et al. (2014) Genetics and biomarkers of moyamoya disease: the significance of RNF213 as a susceptibility gene. J Stroke 16: 65.

8. Kure S (2017) Future Clinical Perspectives on RNF213 in Moyamoya Disease. In: Moyamoya Disease Explored Through RNF213. Springer, Singapore pp. 179-185.

9. Ziefert PD, Karzmark P, Bell-Stephens TE, Steinberg GK, Dorfman LJ (2017) Neurocognitive performance after cerebral revascularization in adult moyamoya disease. Stroke 48: 1514-1517.

10. Bang OY, Fujimura M, Kim SK (2016) The pathophysiology of moyamoya disease: an update. J Stroke 18: 12-20. 
Citation: Adjepong D (2020) Moyamoya Disease -Factors and Prevalence for Perivascular Spaces in Post-Neurological Adult Patients: Neurosurgeon's Perspective. J Emerg Med Trauma Surg Care 7: 045.

11. Bersano A, Guy S, Bedini G, Nava S, Herve D, et al. (2016) Research progresses in understanding the pathophysiology of Moyamoya disease. Cerebrovasc Dis 41: 105-118.

12. Sato S, Kojima D, Shimada Y, Yoshida J, Fujimoto K, et al. (2018) Preoperatively reduced cerebrovascular contractile reactivity to hypocapnia by hyperventilation is associated with cerebral hyperperfusion syndrome after arterial bypass surgery for adult patients with cerebra misery perfusion due to ischemic moyamoya disease. J Cereb Blood Flow Metab 38: 1021-1031.

13. Hitomi T, Habu T, Kobayashi H, Okuda H, Harada KH, et al. (2013) Downregulation of Securin by the variant RNF213 R4810K (rs112735431, $\mathrm{G}>\mathrm{A}$ ) reduces angiogenic activity of induced pluripotent stem cell-derived vascular endothelial cells from moyamoya patients. Biochem Biophys Res Commun 438: 13-19.

14. Kraemer M, Huynh QB, Wieczorek D, Balliu B, Mikat B, et al. (2018) Distinctive facial features in idiopathic Moyamoya disease in Caucasians: a first systematic analysis. Peer J 6: e4740.

15. Phi JH, Wang KC, Lee JY, Kim SK (2015) Moyamoya syndrome: window of moyamoya disease. J Korean Neurosurg Soc 57: 408.

16. Guey S, Kraemer M, Grangeon L, Riant F, Kossorotoff M, et al. (2017) Genetics of Moyamoya Beyond RNF213: Monogenic Moyamoya Syndromes. In: Moyamoya Disease Explored Through RNF213. Springer, Singapore pp. 103-118.

17. Koizumi A, Kobayashi H, Liu W, Fujii Y, Senevirathna ST, et al. (2013) R4810K, a polymorphism of RNF213, the susceptibility gene for moyamoya disease, is associated with blood pressure. Environ Health Prev Med 18: 121.

18. Yamada H, Saga I, Kojima A, Horiguchi T (2019) Short-Term Spontaneous Resolution of Ruptured Peripheral Aneurysm in Moyamoya Disease. World Neurosurg126: 247-251.

19. Hughes JW, Wyckoff JA, Hollander AS, Derdeyn CP, McGill JB (2016) Moyamoya syndrome causing stroke in young women with type 1 diabetes. J Diabetes Complications 30: 1640-1642.
20. Im SH, Oh CW, Kwon OK, Kim JE, Han DH (2005) Moyamoya disease associated with Graves disease: special considerations regarding clinical significance and management. J Neurosurg 102: 1013-1017.

21. Weinberg DG, Arnaout OM, Rahme RJ, Aoun SG, Batjer HH, et al. (2011) Moyamoya disease: a review of histopathology, biochemistry, and genetics. Neurosurg Focus 30: E20.

22. Kim JS (2016) Moyamoya disease: epidemiology, clinical features, and diagnosis. J Stroke 18: 2.

23. Wouters A, Smets I, Van den Noortgate W, Steinberg GK, Lemmens R (2019) Cerebrovascular events after surgery versus conservative therapy for moyamoya disease: a meta-analysis. Acta Neurologica Belgica 18: 1-9.

24. Brown C, Rubin JE (2018) Moyamoya Disease. Pediatric Anesthesia: A Problem-Based. Learning Approach 17: 295.

25. Yeh SJ, Tang SC, Tsai LK, Jeng JS (2018) Abstract WP386: AgeDependent Ultrasonographic Changes After Indirect Revascularization Surgery in Patients with Moyamoya Disease. Stroke 49: AWP386.

26. Yokoya S, Hino A, Goto Y, Oka H (2019) Middle Meningeal-Middle Cerebral Artery Anastomosis for Moyamoya Disease. World Neurosurg 129: 5-8.

27. Roder C, Nayak NR, Khan N, Tatagiba M, Inoue I, et al. (2010) Genetics of Moyamoya disease. J Hum Genetics 55: 711.

28. Ohkubo K, Sakai Y, Inoue H, Akamine S, Ishizaki Y, et al. (2015) Moyamoya disease susceptibility gene RNF213 links inflammatory and angiogenic signals in endothelial cells. Sci Rep 5: 13191.

29. Gagunashvili AN, Osaka L, Kelberman D, Munot P, Bacchelli C, et al. (2019) Novel missense variants in the RNF213 gene from a European family with Moyamoya disease. Hum Genome Var 6: 1-5. 


\section{di \\ нетан}

Advances In Industrial Biotechnology | ISSN: 2639-5665

Advances In Microbiology Research | ISSN: 2689-694X

Archives Of Surgery And Surgical Education | ISSN: 2689-3126

Archives Of Urology

Archives Of Zoological Studies | ISSN: 2640-7779

Current Trends Medical And Biological Engineering

International Journal Of Case Reports And Therapeutic Studies | ISSN: 2689-310X Journal Of Addiction \& Addictive Disorders | ISSN: 2578-7276

Journal Of Agronomy \& Agricultural Science | ISSN: 2689-8292

Journal Of AIDS Clinical Research \& STDs | ISSN: 2572-7370

Journal Of Alcoholism Drug Abuse \& Substance Dependence | ISSN: 2572-9594

Journal Of Allergy Disorders \& Therapy | ISSN: 2470-749X

Journal Of Alternative Complementary \& Integrative Medicine | ISSN: 2470-7562

Journal Of Alzheimers \& Neurodegenerative Diseases | ISSN: 2572-9608

Journal Of Anesthesia \& Clinical Care | ISSN: 2378-8879

Journal Of Angiology \& Vascular Surgery | ISSN: 2572-7397

Journal Of Animal Research \& Veterinary Science | ISSN: 2639-3751

Journal Of Aquaculture \& Fisheries | ISSN: 2576-5523

Journal Of Atmospheric \& Earth Sciences | ISSN: 2689-8780

Journal Of Biotech Research \& Biochemistry

Journal Of Brain \& Neuroscience Research

Journal Of Cancer Biology \& Treatment | ISSN: 2470-7546

Journal Of Cardiology Study \& Research | ISSN: 2640-768X

Journal Of Cell Biology \& Cell Metabolism | ISSN: 2381-1943

Journal Of Clinical Dermatology \& Therapy | ISSN: 2378-8771

Journal Of Clinical Immunology \& Immunotherapy | ISSN: 2378-8844

Journal Of Clinical Studies \& Medical Case Reports | ISSN: 2378-8801

Journal Of Community Medicine \& Public Health Care | ISSN: 2381-1978

Journal Of Cytology \& Tissue Biology | ISSN: 2378-9107

Journal Of Dairy Research \& Technology | ISSN: 2688-9315

Journal Of Dentistry Oral Health \& Cosmesis | ISSN: 2473-6783

Journal Of Diabetes \& Metabolic Disorders | ISSN: 2381-201X

Journal Of Emergency Medicine Trauma \& Surgical Care | ISSN: 2378-8798

Journal Of Environmental Science Current Research | ISSN: 2643-5020

Journal Of Food Science \& Nutrition | ISSN: 2470-1076

Journal Of Forensic Legal \& Investigative Sciences | ISSN: 2473-733X

Journal Of Gastroenterology \& Hepatology Research | ISSN: 2574-2566
Journal Of Genetics \& Genomic Sciences | ISSN: 2574-2485

Journal Of Gerontology \& Geriatric Medicine | ISSN: 2381-8662

Journal Of Hematology Blood Transfusion \& Disorders | ISSN: 2572-2999

Journal Of Hospice \& Palliative Medical Care

Journal Of Human Endocrinology | ISSN: 2572-9640

Journal Of Infectious \& Non Infectious Diseases | ISSN: 2381-8654

Journal Of Internal Medicine \& Primary Healthcare | ISSN: 2574-2493

Journal Of Light \& Laser Current Trends

Journal Of Medicine Study \& Research | ISSN: 2639-5657

Journal Of Modern Chemical Sciences

Journal Of Nanotechnology Nanomedicine \& Nanobiotechnology | ISSN: 2381-2044

Journal Of Neonatology \& Clinical Pediatrics | ISSN: 2378-878X

Journal Of Nephrology \& Renal Therapy | ISSN: 2473-7313

Journal Of Non Invasive Vascular Investigation | ISSN: 2572-7400

Journal Of Nuclear Medicine Radiology \& Radiation Therapy | ISSN: 2572-7419

Journal Of Obesity \& Weight Loss | ISSN: 2473-7372

Journal Of Ophthalmology \& Clinical Research | ISSN: 2378-8887

Journal Of Orthopedic Research \& Physiotherapy | ISSN: 2381-2052

Journal Of Otolaryngology Head \& Neck Surgery | ISSN: 2573-010X

Journal Of Pathology Clinical \& Medical Research

Journal Of Pharmacology Pharmaceutics \& Pharmacovigilance | ISSN: 2639-5649

Journal Of Physical Medicine Rehabilitation \& Disabilities | ISSN: 2381-8670

Journal Of Plant Science Current Research | ISSN: 2639-3743

Journal Of Practical \& Professional Nursing | ISSN: 2639-5681

Journal Of Protein Research \& Bioinformatics

Journal Of Psychiatry Depression \& Anxiety | ISSN: 2573-0150

Journal Of Pulmonary Medicine \& Respiratory Research | ISSN: 2573-0177

Journal Of Reproductive Medicine Gynaecology \& Obstetrics | ISSN: 2574-2574

Journal Of Stem Cells Research Development \& Therapy | ISSN: 2381-2060

Journal Of Surgery Current Trends \& Innovations | ISSN: 2578-7284

Journal Of Toxicology Current Research | ISSN: 2639-3735

Journal Of Translational Science And Research

Journal Of Vaccines Research \& Vaccination | ISSN: 2573-0193

Journal Of Virology \& Antivirals

Sports Medicine And Injury Care Journal | ISSN: 2689-8829

Trends In Anatomy \& Physiology | ISSN: 2640-7752

Submit Your Manuscript: http://www.heraldopenaccess.us/Online-Submission.php 